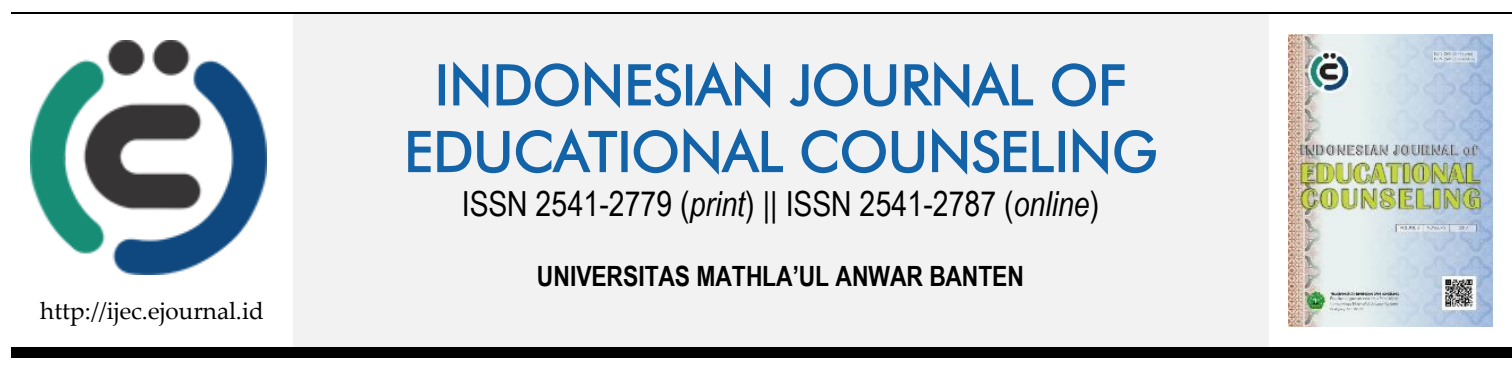

Research Based Article

\title{
Disruptive Behavior dan Bentuk Perlakuan Guru
}

\author{
Annur Aliyyu ${ }^{1}$ \\ ${ }^{1}$ Universitas Pendidikan Indonesia
}

\begin{tabular}{|c|c|}
\hline Article History & ABSTRACT \\
\hline
\end{tabular}

Received in revised form: CONFIGURATION. This study aims to determine the theoretical concepts, 01.04.2019

Accepted: 10.04 .2019

Available online: 05.08 .2019 acceptability, practicability, and effectiveness of guidelines for rational emotive counseling, homework assignment techniques, and confrontation techniques. This research is development research with steps: design preparation, design validation, design testing, and design revision. Questionnaire and interview methods collected data, and the data collected were analyzed using descriptive analysis techniques. The results showed: (1) Theoretically rational emotive counseling procedures homework assignment techniques and confrontation techniques include steps: showing the counselee that the problem faced is related to irrational beliefs, bringing the counselee to the opposite stage of consciousness by showing that the counselee is maintained emotional disturbances to stay active by always thinking illogically, correcting the thoughts of the counselee and leaving irrational ideas, challenging the counselee to develop rational philosophies. The difference between the two lies in the things done at each step; (2) Acceptability of rational emotive counseling guidelines for homework assignment techniques and confrontation techniques; (3) The practicality of rational emotive counseling guidelines for homework assignment techniques and confrontation techniques is very high; (4) The effectiveness of rational emotive counseling guidelines for homework assignment techniques and confrontation techniques is very high.

KEYWORDS: Confrontation Techniques, Homework Assignment Techniques, Rational Emotive Counseling.

DOI: $10.30653 / 001.201933 .101$

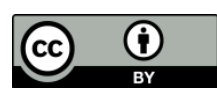

This is an open access article distributed under the terms of the Creative Commons Attribution 4.0 International License, which permits unrestricted use, distribution, and reproduction in any medium, provided the original work is properly cited. (c) 2019 Annur Aliyyu.

\section{PENDAHULUAN}

Revolusi industri 4.0 membawa implikasi berupa tantangan-tantangan baru dalam dunia pendidikan (Suwardana, 2018). Era dimana segala sesuatu bisa dilakukan secara mudah dan cepat karena sebagian besar kehidupan sudah mulai dilakukan secara digital, memberikan dampak berupa kemudahan sekaligus tantangan baru dalam praktik pendidikan. Maraknya bidang-bidang pekerjaan yang sudah mulai digantikan oleh mesin atau robot, menantang dunia pendidikan untuk semakin meningkatkan mutu lulusan

${ }^{1}$ Corresponding author's address: Mahasiswa S2 Bimbingan dan Konseling Pascasarjana UPI, Indonesia. 
agar memiliki daya saing sesuai tuntutan zaman (Aurachman, 2018). Sementara itu, siswa yang dihadapi pendidik saat ini adalah generasi $Z$ yang sejak lahir sudah akrab dengan teknologi, khususnya internet. Di satu sisi, keberadaan internet ini sangat menguntungkan sebagai sumber informasi dan pembelajaran (Maryono \& Istiana, 2007), tetapi di sisi lain melahirkan generasi yang ingin serba mudah, instan, malas bekerja keras, dan bahkan menurut Qomariyah (2009) cenderung mengarah pada peniruan perilakuperilaku negatif dari dunia maya, termasuk perilaku negatif di sekolah yang bisa mengganggu kegiatan pembelajaran.

Perilaku mengganggu (disruptive behavior) di sekolah telah menjadi perhatian lebih bagi para pendidik, tenaga kependidikan, dan profesional kesehatan mental (Hafen et al, 2015), karena menghadapi perilaku menggganggu di kelas adalah perjuangan sehari-hari bagi banyak pendidik (McKissick et al, 2010). Ada banyak waktu terbuang yang dihabiskan guru untuk mendisiplinkan dan mengarahkan siswa yang berperilaku mengganggu, karena jika dibiarkan dapat berdampak pada siswa lain di kelas. Perilaku seperti itu dapat menyebabkan berkurangnya waktu belajar, menurunnya kinerja akademik, dan menurunkan skor nilai tes standar (Canter, Paige, Roth, Romero, \& Carroll, 2004).

Selain itu, penelitian Ramp, Ulrich, dan Dulaney (1971) menunjukkan bahwa mayoritas guru harus merancang teknik manajemen kelas mereka sendiri, karena pendidikan secara umum tidak memiliki prinsip-prinsip yang efektif untuk membantu guru, dan hal ini merupakan salah satu kontributor kelelahan (Kokkinos, Panayiotou, \& Davazoglou, 2005) dan stres di kalangan para guru (Supaporn, Dodds, \& Griffin, 2003). Selanjutnya, studi lain menemukan bahwa guru yang mengalami tingkat stres yang tinggi akibat dari perilaku siswa yang buruk adalah guru dengan tingkat efikasi diri dan kemampuan manajemen kelas yang rendah (Klassen \& Chiu, 2010). Dengan demikian, kurangnya kemampuan guru untuk mengatur perilaku kelas, dapat berkontribusi terhadap pergesekan guru di lapangan. Hampir setengah dari guru baru yang meninggalkan profesinya dalam waktu lima tahun, menyebutkan bahwa perilaku mengganggu siswa sebagai salah satu alasan utama mereka pergi meninggalkan profesi tersebut (Ingersoll, 2002).

Menghadapi perilaku siswa yang mengganggu di kelas tampaknya menjadi bagian yang tak bisa dihindari di kalangan pendidik (Anderson, 1999, Nordstrom, Bartels, \& Bucy, 2009, Siedman, 2005). Guru menghabiskan lebih banyak waktu untuk mendisiplinkan siswa daripada instruksi pelajaran di kelas karena pembelajaran tidak berjalan dengan baik, akibat perilaku buruk beberapa siswa (Rosenberg dan Jackman, 2003). Dinyatakan bahwa dilema paling sulit yang dihadapi guru-guru saat ini adalah perilaku "bermasalah" (White et al, 2001), karena menunjukkan peningkatan siswa dengan masalah perilaku mengganggu di kelas. Para pendidik didorong untuk mengambil beberapa tindakan untuk menghentikan perilaku mengganggu, mengaktifkan kembali partisipasi siswa dalam proses pembelajaran, dan mencegah siswa lainnya terpengaruh oleh kondisi tersebut (Nordstrom, Bartels \& Bucy, 2009).

Isu-isu perilaku siswa yang mengganggu dan manajemen kelas telah menarik minat para peneliti dalam bidang ilmu psikologi dan pendidikan. Perilaku siswa di kelas telah diteliti dari berbagai perspektif seperti perilaku mengganggu yang paling sering, perilaku mengganggu yang paling menyusahkan, dan perilaku yang paling menjadi perhatian guru (Haroun \& O'Hanlon, 1997). Sementara masalah manajemen kelas menjadi 
tantangan bagi guru saat ini dan kemungkinan akan terus menjadi perhatian utama bagi guru di masa depan (Kullina, Silverman, \& Keating, 2000). Guru dari semua tingkatan sekolah melaporkan bahwa manajemen kelas adalah salah satu aspek pengajaran yang paling menantang sekaligus mengganggu (Edwards et al, 1998). Manajemen kelas adalah jantung dari efektivitas guru di kelas. Manajemen kelas mengacu pada berbagai perilaku guru, dan salah satu yang paling penting adalah mengelola perilaku siswa. FernandezBalboa (1991) melaporkan perilaku buruk beberapa orang siswa dapat mengganggu siswa lainnya di kelas, termasuk guru, dari fokus terhadap pembelajaran. Kemampuan untuk mengelola perilaku siswa juga merupakan karakteristik utama yang membedakan antara guru yang efektif dan yang tidak efektif (Siedentop \& Tannehill, 1999).

Isu lain yang sedang menjadi perhatian utama US Public Health Service (Blue \& Surgeon, 2000) terkait perilaku mengganggu selain manajemen kelas, adalah kurangnya intervensi bimbingan dan konseling yang responsif di sekolah-sekolah. Sekolah berada dalam posisi unik untuk mengidentifikasi anak-anak yang menderita gangguan perilaku dan menyediakan intervensi awal yang dapat mencegah timbulnya masalah yang lebih parah (Meany-Walen, Bratton, \& Kottman, 2014). Ketika anak-anak menunjukkan perilaku yang mengganggu, hubungan kritis antara guru dan siswa mungkin rusak atau tegang (Abidin \& Robinson, 2002; Hamre, Pianta, Downer, \& Mashburn, 2008; Myers \& Pianta, 2008). Tanpa intervensi yang tepat, perilaku mengganggu pada anak menunjukkan tingkat stabilitas yang tinggi dari waktu ke waktu, bahkan sering mengarah pada perkembangan sejumlah masalah serius di seluruh rentang kehidupan anak, termasuk perilaku antisosial, kekerasan, penyalahgunaan narkoba, dan kenakalan remaja (Mental Health America, 2012).

Beberapa penelitian terkait intervensi yang sudah dilakukan, diantaranya penelitian Bicard et al (2012) tentang pengaturan tempat duduk, Cihak, Kirk, \& Boon (2009) tentang tootles intervention, Donaldson et al (2011) tentang good behavior game, McKissick (2010) tentang kontingensi ganda, dan Meany-Walen, Bratton, dan Kottman (2014) yang meneliti tentang intervensi dengan menggunakan Adlerian Play Therapy. Diantara penelitian yang sudah ada, penelitian terkait intervensi bimbingan dan konseling masih sangat terbatas. Padahal masalah ini bukan hanya menjadi tanggung jawab guru kelas atau guru mata pelajaran saja, mengingat prevalensi dan lintasan perilaku mengganggu siswa di kelas ini cukup besar, maka penulis berpendapat bahwa penelitian terkait identifikasi intervensi bimbingan dan konseling untuk menargetkan perilaku ini adalah prioritas.

Berdasarkan penjelasan di atas, tujuan dari penelitian ini adalah mengidentifikasi perilaku mengganggu (disruptive behavior) yang mucul di kelas atau sekolah, tindakan yang diambil oleh guru mata pelajaran, guru kelas/wali kelas, serta intervensi bimbingan dan konseling yang telah dilakukan untuk mengatasi perilaku tersebut.

\section{METODE}

Metode penelitian yang digunakan adalah metode penelitian deskriptif. Penelitian deskriptif adalah penelitian yang berusaha mendeskripsikan suatu gejala, peristiwa, kejadian, dan menemukan pengetahuan seluas-luasnya pada suatu periode tertentu (Syah, 2010). Dengan penelitian deskriptif, peneliti berusaha mendekripsikan peristiwa atau kejadian yang menjadi pusat perhatian tanpa memberikan perlakuan khusus terhadap peristiwa tersebut. Teknik penelitian yang digunakan untuk pengumpulan data 
adalah melalui survey berupa penyebaran angket mengenai perilaku mengganggu (disruptive behavior) siswa dan perlakuan guru mata pelajaran, guru kelas/wali kelas, serta intervensi bimbingan dan konseling yang dilakukan oleh guru bimbingan dan konseling di sekolah.

Subjek penelitian terdiri dari Guru Mata Pelajaran, Guru Kelas/Wali Kelas, dan Guru Bimbingan dan Konseling, mulai jenjang pendidikan SD, SMP, dan SMA/SMK/Sederajat. Instrumen penelitian yang digunakan adalah angket mengenai perilaku mengganggu (disruptive behavior) siswa yang diadaptasi dari Disruptive Behavior Scale Professed by Students (DBS-PS) yang dikembangkan oleh Feliciano H Veiga (2008) dari Universidade de Lisboa, Portugal. dan bentuk perlakuan guru ( guru mata pelajaran, guru kelas/wali kelas, dan guru bimbingan dan konseling) di sekolah yang dikonstruk melalui google form di link: https://goo.gl/forms/uKprQEYXEPzYDxDA3 dan disebarkan secara online melalui aplikasi sosial media watsapp pada tanggal 21-23 Maret 2009. Pengolahan data dilakukan melalui aplikasi Statistical Product and Service Solutions (SPSS) untuk diambil data pemeringkatan (ranking) dari perilaku mengganggu yang muncul serta bentuk perlakuan guru (guru mata pelajaran, guru kelas/wali kelas, dan guru bk) yang dilakukan di sekolah.

\section{HASIL DAN PEMBAHASAN}

Data hasil penelitian diperoleh dari 70 orang responden, yang merupakan guru mata pelajaran, guru kelas/wali kelas, dan guru BK mulai dari jenjang SD, SMP, dan SMA/SMK/Sederajat. Jika berdasarkan jenis guru, maka guru mata pelajaran sebanyak 43 orang, guru kelas/wali kelas sebanyak 9 orang, dan sisanya adalah guru BK sebanyak 18 orang. Jika berdasarkan jenjang, sebanyak 19 orang guru dari jenjang SD, 6 orang guru dari jenjang SMP, dan sisanya sebanyak 45 orang guru dari jenjang SMA/SMK/Sederajat. Data hasil survei diolah dengan aplikasi SPSS dan diperoleh hasil berupa peringkatan (ranking) perilaku menganggu (disruptive behavior) yang disajikan pada Tabel 1.

Tabel 1 menjelaskan bahwa hampir di setiap item, terdapat siswa yang memiliki perilaku mengganggu tersebut, meskipun jumlahnya berbeda-beda di tiap sekolah. Urutan item dengan skor tertinggi hingga terendah mulai dari peringkat (ranking) ke-1 hingga ke-11 terdapat di semua sekolah dimana responden bekerja. Artinya perilaku mengganggu (disruptive behavior) ada di semua sekolah. Padahal menurut McCaskey (2015) disruptive behavior adalah perilaku yang mengganggu kegiatan mengajar guru atau mengganggu pembelajaran siswa lainnya yang menyebabkan ketidakamanan secara psikologis dan fisik.

Perilaku disruptif siswa di kelas dikenal juga sebagai kenakalan atau partisipasi negatif siswa di dalam kelas (Asizah, 2015). Perilaku ini sangat merugikan baik untuk individu siswa itu sendiri, siswa lainnya, maupun guru. Kajian (Ghazi et al., 2013) menemukan bahwa seorang anak yang mengganggu dapat menciptakan kegaduhan dan mengganggu teman yang duduk disebelahnya. Dengan adanya siswa yang berperilaku mengganggu membuat waktu guru dalam menjelaskan materi pelajaran akhirnya menjadi berkurang karena harus ada sebagian waktu yang digunakan guru untuk mengatasi siswa yang berperilaku mengganggu tersebut (Rosenberg \& Jackman, 2003). 
Tabel 1. Pemeringkatan (Ranking) Disruptive Behavior di Sekolah Berdasarkan Urutan Item Soal

\begin{tabular}{|c|c|c|c|c|c|}
\hline No. & Item & $\begin{array}{l}\text { Total } \\
\text { Skor }\end{array}$ & $\begin{array}{l}\text { Skor } \\
\text { Max }\end{array}$ & $\%$ & Ranking \\
\hline 1 & Merusak barang atau fasilitas sekolah & 90 & 280 & 8,12 & 6 \\
\hline 2 & $\begin{array}{l}\text { Menyerang secara fisik atau berkelahi dengan } \\
\text { teman sekelas atau teman satu sekolah }\end{array}$ & 82 & 280 & 7,39 & $7 a$ \\
\hline 3 & Patuh terhadap guru* & 49 & 280 & 4,42 & 10 \\
\hline 4 & Berbicara tanpa izin, mengganggu kelas & 118 & 280 & 10,64 & 3 \\
\hline 5 & Menyerang guru secara fisik & 9 & 280 & 0,81 & 16 \\
\hline 6 & Berbicara kasar di dalam kelas & 82 & 280 & 7,39 & $7 \mathrm{~b}$ \\
\hline 7 & $\begin{array}{l}\text { Datang ke sekolah di bawah pengaruh alkohol } \\
\text { atau obat-obatan terlarang }\end{array}$ & 19 & 280 & 1,71 & 15 \\
\hline 8 & $\begin{array}{l}\text { Beranjak dari tempat duduk, berteriak, dan } \\
\text { menyebabkan gangguan lainnya }\end{array}$ & 65 & 280 & 5,86 & 9 \\
\hline 9 & $\begin{array}{l}\text { Lupa membawa buku pelajaran atau } \\
\text { perlengkapan belajar lainnya }\end{array}$ & 122 & 280 & 11,00 & 2 \\
\hline 10 & Mencuri di sekolah & 38 & 280 & 3,43 & 12 \\
\hline 11 & $\begin{array}{l}\text { Menyerang atau melawan guru secara verbal } \\
\text { (menggunakan kata-kata) }\end{array}$ & 37 & 280 & 3,34 & 13 \\
\hline 12 & Tiba di sekolah tepat waktu* & 41 & 280 & 3,70 & 11 \\
\hline 13 & Terlambat masuk ke dalam kelas & 114 & 280 & 10,28 & 4 \\
\hline 14 & $\begin{array}{l}\text { Tidak memperhatikan pelajaran di dalam } \\
\text { kelas }\end{array}$ & 127 & 280 & 11,45 & 1 \\
\hline 15 & $\begin{array}{l}\text { Menyerang teman sekelas secara verbal } \\
\text { (menggunakan kata-kata) }\end{array}$ & 93 & 280 & 8,39 & 5 \\
\hline 16 & $\begin{array}{l}\text { Mengancam teman, guru, atau staf sekolah } \\
\text { lainnya di kelas atau di sekolah }\end{array}$ & 23 & 280 & 2,07 & 14 \\
\hline
\end{tabular}

Item dengan skor urutan ke 12 hingga ke-16 tidak terjadi di semua sekolah. Meskipun demikian, adanya responden yang menyatakan bahwa perilaku tersebut terjadi di sekolahnya patut menjadi kewaspadaan untuk semua pihak agar dilakukan upayaupaya pencegahan sehingga perilaku-perilaku tersebut tidak perlu terjadi. Serangkaian penelitian yang dilakukan oleh Barkley, 2007; Brinkmeyer \& Eyberg, 2003; Janosz, Le Blanc, Boulerice, \& Tremblay, 2000; Mental Health America, 2009; Webster-Stratton \& Reid, 2003 menunjukkan bahwa jika tidak segera dilakukan intervensi yang tepat, perilaku mengganggu pada anak menunjukkan tingkat stabilitas yang tinggi dari waktu ke waktu, bahkan sering mengarah pada perkembangan sejumlah masalah serius di seluruh rentang kehidupan anak, termasuk perilaku antisosial, kekerasan, penyalahgunaan narkoba, dan kenakalan remaja.

Hasil penelitian berikutnya adalah mengenai deskripsi bentuk perlakuan guru (mata pelajaran dan guru kelas) di sekolah serta intervensi guru bimbingan dan konseling, yang dibedakan berdasarkan jenjang, lama mengajar, dan usia guru, dapat dilihat pada Tabel 2. 
Tabel 2. Bentuk Perlakuan Guru dan Intervensi Bimbingan dan Konseling di Sekolah

\begin{tabular}{|c|c|c|}
\hline No. Res & Guru Mapel/BK & Bentuk Perlakuan Guru/Intervensi BK \\
\hline 1 & Guru BK & Konseling kelompok teknik shaping perilaku \\
\hline 2 & Guru BK & Layanan konseling individu \\
\hline 3 & Guru Mapel & $\begin{array}{l}\text { Teguran secara verbal, pendekatan dan pengarahan, } \\
\text { dan berkoordinasi dengan guru BK dan wali kelas }\end{array}$ \\
\hline 4 & Guru Mapel & Didekati di beri perhatian \\
\hline 5 & Guru Mapel & $\begin{array}{l}\text { Memberi nasehat sekaligus peringatan, bahkan } \\
\text { mungkin sampai sanksi. }\end{array}$ \\
\hline 6 & Guru BK & $\begin{array}{l}\text { Diajak berbicara dan dicari latar belakang serta prilaku } \\
\text { seperti apa yang seharusnya dilakukan atau } \\
\text { ditampilkan }\end{array}$ \\
\hline 7 & Guru Mapel & Menasihatinya \\
\hline 8 & Guru BK & Dipanggil ke ruang bk untuk konseling \\
\hline 9 & Guru BK & Memanggil siswa tsb keruang bk \\
\hline 10 & Guru Mapel & $\begin{array}{l}\text { Mencari waktu luang untuk diskusi kenapa ia } \\
\text { melakukan itu }\end{array}$ \\
\hline 11 & Guru BK & REBT dan Client centered counseling \\
\hline 12 & Guru Mapel & dipanggil diberi nasehat kadang ada tindakan fisik \\
\hline 13 & Guru Mapel & $\begin{array}{l}\text { Mewawancarai siswa utk mengetahui kepribadian serta } \\
\text { latar belakang siswa }\end{array}$ \\
\hline 14 & Guru Mapel & Dipanggil dan diberikan arahan \\
\hline 15 & Guru Mapel & $\begin{array}{l}\text { Menegur, jika masih tidak berubah, di laporkan ke } \\
\text { pihak sekolah }\end{array}$ \\
\hline 16 & Guru BK & $\begin{array}{l}\text { Identifikasi, berikan teguran, kritik membangun dari } \\
\text { teman bahwa perilaku nya meresahkan, memberikan } \\
\text { konseling self management, dibahas setiap konseling } \\
\text { sesuai format yang diberikan. Progres direward. Blm } \\
\text { berhasil, kerjasama dengan orangtuanya }\end{array}$ \\
\hline 17 & Guru BK & Konseling Individu \\
\hline 18 & Guru Mapel & Diberi nasehat dan poin \\
\hline 19 & Guru Mapel & Dipanggil,kemudian di ajak ngobrol,di nasihati \\
\hline 20 & Guru BK & Bimbingan dan konseling individu atau kelompok \\
\hline 21 & Guru Mapel & $\begin{array}{l}\text { Pertama kali memperingatinya secara baik-baik, jika } \\
\text { masih berlanjut diberi sanksi lebih lanjut dan } \\
\text { melaporkannya kepada guru BK juga wali kelasnya } \\
\text { agar segera ditangani }\end{array}$ \\
\hline 22 & Guru Mapel & $\begin{array}{l}\text { Melakukan pendekatan internal memahami akar } \\
\text { permasalahannya melalui informasi teman sekitar dan } \\
\text { mencoba mencari tau masalah siswa tsb kepada wali } \\
\text { kelasnya. Dan bersama wali kelas mencoba } \\
\text { menyelesaikan permasalahan tsb. Dalam KBM saya } \\
\text { memberikan perhatiam lebih pada siswa tersebut, } \\
\text { dengan memberi kesempatan dia untuk menjawab atau }\end{array}$ \\
\hline
\end{tabular}




\begin{tabular}{|c|c|c|}
\hline No. Res & Guru Mapel/BK & Bentuk Perlakuan Guru/Intervensi BK \\
\hline & & $\begin{array}{l}\text { sekedar bertanya/berkomunikasi ringan. Yang jelas } \\
\text { pasti menegur dan menasihati secara halus }\end{array}$ \\
\hline 23 & Guru BK & Konseling individual \\
\hline 24 & Guru Mapel & Diberi nasehat \\
\hline 25 & Guru Mapel & $\begin{array}{l}\text { Dipanggil,diberI nasehat agar tidak mengulangi } \\
\text { perilaku sepertI itu }\end{array}$ \\
\hline 26 & Guru Mapel & $\begin{array}{l}\text { 1. Bertanya 2. Mengajak bicara kenapa melakukan hal } \\
\text { tersebut } 3 \text {. Mengingatkan untuk tidak. mengulang } \\
\text { perbuatan tersebut } 4 \text {. Jika agak berat memberi sangsi } 5 \text {. } \\
\text { Jika ada perubahan yang baik diberi pujian atau } \\
\text { reinforcement }\end{array}$ \\
\hline 27 & Guru Mapel & Mencari penyebabnya \\
\hline 28 & Guru Mapel & Memanggil anak tersebut dan menasehatinya \\
\hline 29 & Guru Mapel & Meluruskan perilakunya \\
\hline 30 & Guru Mapel & $\begin{array}{l}\text { Langkah pertama pendekatan dengan pelaku } \\
\text { kemudian identifikasi latar belakang pelaku, mengapa } \\
\text { pelaku melakukan seperti itu }\end{array}$ \\
\hline 31 & Guru Mapel & $\begin{array}{l}\text { berusaha melakukan pendekatan terhadap siswa yang } \\
\text { bersifat mengganggu, dan berupaya mencari tahu apa } \\
\text { sebenarnya penyebab utamanya ,karena bisa berbagai } \\
\text { faktor diantaranya mungkin karena brokenhome }\end{array}$ \\
\hline 32 & Guru Mapel & $\begin{array}{l}\text { Memberikan teguran dan memberikan arahan untuk } \\
\text { supaya bisa mengikuti pembelajaran di dalam kelas } \\
\text { dengan baik }\end{array}$ \\
\hline 33 & Guru Mapel & $\begin{array}{l}\text { Menasihati dengan cara yang baik. Kasus tertentu } \\
\text { diberikan hukuman yang mendidik }\end{array}$ \\
\hline 34 & Guru Mapel & $\begin{array}{l}\text { Diberi peringatan secara verbal, dan melakukan } \\
\text { pendekatan }\end{array}$ \\
\hline 35 & Guru Mapel & Keteladanan \\
\hline 36 & Guru Mapel & Menasehati, mengajak diskusi \\
\hline 37 & Guru Kelas & $\begin{array}{l}\text { Berbicara empat mata, menanyakan perasaan dan } \\
\text { mencari tahu sebab perlakuannya bersama. } \\
\text { Mengarahkan siswa untuk mengelola emosinya. } \\
\text { Membuat kesepakatan konsekuensi yang akan diterima } \\
\text { jika masih melakukan }\end{array}$ \\
\hline 38 & Guru Kelas & $\begin{array}{l}\text { Memberikan peraturan, dan jika melanggar aturan d } \\
\text { peringati menggunakan lisan, jika masih juga d lakukan } \\
\text { maka akan d beri sanksi berupa menulis }\end{array}$ \\
\hline 39 & Guru Kelas & Diajak mengobrol sambil menasehati \\
\hline 40 & Guru Kelas & Memberikan teguran \\
\hline 41 & Guru Mapel & $\begin{array}{l}\text { Menasehati anak, mencari tau kenapa anak seperti itu, } \\
\text { berbicara dengan ortu dan bekerja sama dengan orang } \\
\text { tua }\end{array}$ \\
\hline 42 & Guru Mapel & $\begin{array}{l}\text { Diberikan pengarahan secara signifikan dan ada } \\
\text { punishment sesuai pelanggaran yang dibuatnya }\end{array}$ \\
\hline 43 & Guru Mapel & Memberi tahu bahwasanya tindakan nya salah \\
\hline
\end{tabular}




\begin{tabular}{|c|c|c|}
\hline No. Res & Guru Mapel/BK & Bentuk Perlakuan Guru/Intervensi BK \\
\hline 44 & Guru Mapel & Melempar tanggungjawab ke guru yang lebih senior \\
\hline 45 & Guru Kelas & $\begin{array}{l}\text { Melakukan penelusuran tentang penyebab berperilaku } \\
\text { seperti itu - melakukan konseling - komunikasikan } \\
\text { dengan orang tua tentang penanganan anak tsb }\end{array}$ \\
\hline 46 & Guru Mapel & $\begin{array}{l}\text { Mengajak berbicara secara intens dan mencari tahu } \\
\text { sumber permasalahan dari cerita anak tersebut, } \\
\text { mengambil kesimpulan dan membuat cara penyelasaan } \\
\text { masalah }\end{array}$ \\
\hline 47 & Guru Mapel & Diberikan pengarahan dan bimbingan secara individu \\
\hline 48 & Guru Kelas & Menegur, memberi tugas tambahan \\
\hline 49 & Guru Mapel & Melalui pendekatan kepada anak \\
\hline 50 & Guru Kelas & $\begin{array}{l}\text { Selalu diingatkan untuk perilaku yang baik, diberikan } \\
\text { contoh yang sesuai }\end{array}$ \\
\hline 51 & Guru Mapel & $\begin{array}{l}\text { memberi pengarahan dan pembelajaran mengenai } \\
\text { prilaku yang baik secara terus menerus ... dalam jenjang } \\
\text { waktu kapan dan dimanapun jika siswa tersebut } \\
\text { berbuat kurang baik }\end{array}$ \\
\hline 52 & Guru Mapel & $\begin{array}{l}\text { Diberikan pengarahan, peringatan dan jika terus } \\
\text { terulang diberikan punishment }\end{array}$ \\
\hline 53 & Guru Kelas & $\begin{array}{l}\text { Berdiskusi dengan siswa tersebut secara personal, } \\
\text { dengan beberapa tahapan, jika masih sulit untuk } \\
\text { dirubah perilakunya, didiskusikan dengan orang } \\
\text { tuanya }\end{array}$ \\
\hline 54 & Guru Kelas & $\begin{array}{l}\text { Memberikan motivasi, arahan, penjelasan dan } \\
\text { bimbingan agar siswa tersebut tidak melakukan } \\
\text { peebuatan yang dapat merugikan diri sendiri dan orang } \\
\text { lain, serta dicatat perkebangan sikap sosialnya, apakah } \\
\text { ada perubahan atau tidak }\end{array}$ \\
\hline 55 & Guru Mapel & $\begin{array}{l}\text { Memperingatkan untuk menghilangkan kebiasaan } \\
\text { buruk tersebut }\end{array}$ \\
\hline 56 & Guru Mapel & $\begin{array}{l}\text { Diperlakukan lebih dari anak anak yang lain, } \\
\text { dimaksudkan untuk memperbaiki } \\
\text { disruptive } \\
\text { behaviour, diberi sugesti yang baik baik }\end{array}$ \\
\hline 57 & Guru Kelas & $\begin{array}{l}\text { Pertama lakukan pembicaran } 4 \text { mata secara terhadap } \\
\text { anak (mengikuti dunia anak). Kalaupun masih terjadi } \\
\text { maka lakukan komunikasi dgn kedua orangtua untk } \\
\text { mengetahui akar permasalahan yang nantinya } \\
\text { disesuaikan dgn ungkapan permasalahn anak yang } \\
\text { dihadapi. Peran guru dan orangtua sangat membantu } \\
\text { untk menyelesaikan permasalahan dn mencari } \\
\text { solusinya dgn tujuan adanya perubahan perilaku } \\
\text { terhadap peserta didik }\end{array}$ \\
\hline 58 & Guru BK & $\begin{array}{l}\text { Mengajak siswa untuk berdialog, mencoba memahami } \\
\text { siswa lebih mendalam }\end{array}$ \\
\hline 59 & Guru BK & Konseling individu \\
\hline 60 & Guru BK & Konseling dengan menggunakan teknik CBT \\
\hline
\end{tabular}




\begin{tabular}{lll}
\hline No. Res & Guru Mapel/BK & Bentuk Perlakuan Guru/Intervensi BK \\
\hline 61 & Guru BK & $\begin{array}{l}\text { Konseling Individu dan bimbingan Klasikal secara } \\
\text { lngsung dan memberikan conton lngsung apa dampak } \\
\text { yang akan terjadi bila melakukan hal tersebut }\end{array}$ \\
\hline 62 & Guru BK & Konseling individu \\
\hline 63 & Guru BK & $\begin{array}{l}\text { Konseling Individu jika prilaku dilakukan } \\
\text { perseorangan dan Bimbingan / Konseling Kelompok } \\
\text { jika dilakukan berjamaah dengan menggunakan CBT }\end{array}$ \\
\hline 64 & Guru BK & Konseling Individual \\
\hline 65 & Guru BK & - \\
\hline 66 & Guru Mapel & $\begin{array}{l}\text { Ditegur dinasehati, dibimbing, diarahkan, kepada hal } \\
\text { yang lebih baik }\end{array}$ \\
\hline 67 & Guru Mapel & $\begin{array}{l}\text { Dikomunikasikan dengan pribadi siswanya dan org } \\
\text { tua, ahli agama untuk cari solusi }\end{array}$ \\
\hline 68 & Guru Mapel & - \\
\hline 69 & Guru Mapel & $\begin{array}{l}\text { Tahap awal ditegur, jika setelah ditegur tidak } \\
\text { menunjukkan usaha untuk berubah, maka tahap } \\
\text { berikutnya dikonsultasikan pada guru BK, dan } \\
\text { mengajak bicara orang tua yang bersangkutan (agar } \\
\text { diketahui latar belakang siswa berperilaku } \\
\text { mengganggu), sehingga relatif "membantu" cara } \\
\text { penanganan siswa tersebut }\end{array}$ \\
\hline 70 & Konseling individual, kelompok, kolaborasi \\
\hline 6 & &
\end{tabular}

\section{SIMPULAN}

Secara teoretik prosedur konseling rasional emotif teknik home work assignment maupun teknik konfrontasi meliputi langkah-langkah: 1) menunjukkan kepada konseli bahwa masalah yang dihadapinya berkaitan dengan keyakinannya yang tidak rasional, 2) membawa konseli ke seberang tahap kesadaran dengan menunjukkan bahwa dia sekarang mempertahankan gangguan-gangguan emosional untuk tetap aktif dengan terus menerus berpikir secara tidak logis, 3) memperbaiki pikiran-pikirannya dan meninggalkan gagasan-gagasan irasionalnya, dan 4) menantang konseli mengembangkan filsafat-filsafat yang rasional. Perbedaan di antara keduanya terletak pada hal-hal yang dilakukan pada tiap langkah tersebut.

Hasil penelitian menunjukkan bahwa keterterimaan panduan konseling rasional emotif teknik home work assignment maupun teknik konfrontasi ditunjukkan dengan koefisien keterterimaan sebesar 1,00. Adapun kepraktisan panduan konseling rasional emotif teknik home work assignment maupun teknik konfrontasi tergolong sangat tinggi, dan keefektifan panduan konseling rasional emotif teknik home work assignment maupun teknik konfrontasi tergolong sangat tinggi 


\section{REFERENSI}

Abidin, R. R., \& Robinson, L. L. (2002). Stress, biases, or professionalism: What drives teachers' referral judgments of students with challenging behaviors?. Journal of Emotional and Behavioral Disorders, 10(4), 204-212.

Anderson, J. A. (1999). Faculty responsibility for promoting conflict-free college classrooms. New Directions for Teaching \& Learning, 77, 69-76.

Aurachman, R. (2018). Perancangan influence diagram perhitungan dampak dari revolusi industri 4.0 terhadap pengangguran kerja. Jurnal Teknologi dan Manajemen Industri, 4(2), 7-12.

Bicard, D. F., Ervin, A., Bicard, S. C., \& Baylot-Casey, L. (2012). Differential effects of seating arrangements on disruptive behavior of fifth grade students during independent seatwork. Journal of Applied Behavior Analysis, 45(2), 407-411.

Blue, S. G. R., \& Surgeon, G. U. (2000). The public health service. Washington, DC: US. Department of Health \& Human Services.

Canter, A. S., Paige, L. Z., Roth, M. D., Romero, I., \& Carroll, S. A. (Eds.). (2004). Helping children at home and school II: Handouts for families and educators. Bethesda, MD: National Association of School Psychologists.

Cihak, D. F., Kirk, E. R., \& Boon, R. T. (2009). Effects of classwide positive peer "tootling" to reduce the disruptive classroom behaviors of elementary students with and without disabilities. Journal of Behavioral Education, 18(4), 267-278.

Donaldson, J. M., Vollmer, T. R., Krous, T., Downs, S., \& Berard, K. P. (2011). An evaluation of the good behavior game in kindergarten classrooms. Journal of Applied Behavior Analysis, 44(3), 605-609.

Edwards, J. L., Green, K. E., Lyons, C. A., Rogers, M. S., \& Swords, M. E. (1998). The effects of cognitive coaching and nonverbal classroom management on teacher efficacy and perceptions of school culture. Washington, DC: Education Resources Information Center (ERIC).

Fernández-Balboa, J. M. (1991). Beliefs, interactive thoughts, and actions of physical education student teachers regarding pupil misbehaviors. Journal of Teaching in Physical Education, 11(1), 59-78.

Hafen, C. A., Ruzek, E. A., Gregory, A., Allen, J. P., \& Mikami, A. Y. (2015). Focusing on teacher-student interactions eliminates the negative impact of students' disruptive behavior on teacher perceptions. International Journal of Behavioral Development, 39(5), 426-431. 
Hamre, B. K., Pianta, R. C., Downer, J. T., \& Mashburn, A. J. (2008). Teachers' perceptions of conflict with young students: Looking beyond problem behaviors. Social Development, 17(1), 115-136.

Haroun, R., \& O'Hanlon, C. (1997). Do teachers and students agree in their perception of what school discipline is?. Educational Review, 49(3), 237-250.

Ingersoll, R. M. (2002). The teacher shortage: A case of wrong diagnosis and wrong prescription. NASSP bulletin, 86(631), 16-31.

Klassen, R. M., \& Chiu, M. M. (2010). Effects on teachers' self-efficacy and job satisfaction: Teacher gender, years of experience, and job stress. Journal of Educational Psychology, 102(3), 741-756.

Kokkinos, C. M., Panayiotou, G., \& Davazoglou, A. M. (2005). Correlates of teacher appraisals of student behaviors. Psychology in the Schools, 42(1), 79-89.

Kulinna, P. H., Silverman, S., \& Keating, X. D. (2000). Relationship between teachers' belief systems and actions toward teaching physical activity and fitness. Journal of Teaching in Physical Education, 19(2), 206-221.

Maryono, Y., \& Istiana, B. P. (2007). Teknologi informasi dan komunikasi. Jakarta: Yudhistira.

McKissick, C., Hawkins, R. O., Lentz, F. E., Hailley, J., \& McGuire, S. (2010). Randomizing multiple contingency components to decrease disruptive behaviors and increase student engagement in an urban second-grade classroom. Psychology in the Schools, 47(9), 944-959.

Meany-Walen, K. K., Bratton, S. C., \& Kottman, T. (2014). Effects of Adlerian play therapy on reducing students' disruptive behaviors. Journal of Counseling $\mathcal{E}$ Development, 92(1), 47-56.

Mental Health America (2012). Conduct disorder. Retrieved November 10th, 2012, From http://www.mentalhealthamerica.net.

Myers, S. S., \& Pianta, R. C. (2008). Developmental commentary: Individual and contextual influences on student-teacher relationships and children's early problem behaviors. Journal of Clinical Child \& Adolescent Psychology, 37(3), 600-608.

Nordstrom, C. R., Bartels, L. K., \& Bucy, J. (2009). Predicting and curbing classroom incivility in higher education. College Student Journal, 43(1), 74-86.

Qomariyah, A. N. (2009). Perilaku penggunaan internet pada kalangan remaja di perkotaan. Surabaya: Universitas Airlangga Surabaya.

Ramp, E., Ulrich, R., \& Dulaney, S. (1971). Delayed timeout as a procedure for reducing disruptive classroom behavior: A case study. Journal of Applied Behavior Analysis, 4(3), 235-239. 
Seidman, A. (2005). The learning killer: Disruptive student behavior in the classroom. Reading Improvement, 42(1), 40-47.

Siedentop, D., \& Tannehill, D. (1999). Developing teaching skills in physical education (pp. 335-339). Mountain View: Mayfield.

Supaporn, S., Dodds, P., \& Griffin, L. (2003). An ecological analysis of middle school misbehavior through student and teacher perspectives. Journal of Teaching in Physical Education, 22(3), 328-349.

Suwardana, H. (2018). Revolusi Industri 4. 0 Berbasis Revolusi Mental. JATI UNIK: Jurnal Ilmiah Teknik dan Manajemen Industri, 1(2), 102-110.

Syah, H. (2010). Metodologi penelitian pendidikan pendekatan verifikatif. Yogyakarta: PT. LkiS Printing Cemerlang.

Veiga, F. H. (2008). Disruptive behavior scale professed by students (DBS-PS): development and validation. International Journal of Psychology and Psychological Therapy, 8(2), 203-216.

White, R., Algozzine, B., Audette, R., Marr, M. B., \& Ellis Jr, E. D. (2001). Unified discipline: A school-wide approach for managing problem behavior. Intervention in School and Clinic, 37(1), 3-8. 